\title{
Hadiste Sağlam Nüsha Oluşturma Çalışmaları Adlı Eser Üzerine Notlar
}

\section{Mustafa Avni GÖKDUMAN*}

Akademik sahada sağlam nüsha oluşturmaya matuf metin tenkidini konu edinen çalışmalar bulunmaktadır. Ancak bu çalışmalar geniş yelpazeli olup muhaddislerin sağlam nüsha oluşturma faaliyetlerine teksif edilmemiştir. Mahmut Gurbet'in muhaddislerin sağlam nüsha oluşturma çabalarını konu edinen kitabı bu anlamda ilgi çekicidir. ${ }^{1}$ Giriş, üç bölüm ve sonuçtan oluşan eserin Giriş'inde konu, amaç, metot ve kaynakların yanı sıra kitapta etraflıca incelenmesi beklenen kavramlardan yalnızca "nüsha, sahîfe ve cüz" yüzeysel olarak ele alınmış, ayrıca Kurân’n mushaf haline getirilip çoğaltılmasının sağlam hadis nüshası oluşturma faaliyetlerine ne tür bir katkıda bulunduğuna değinilmiştir. Birinci Bölüm'de Batıda ve İslâm âlemindeki metin tenkidi faaliyetleri işlenirken İkinci Bölüm'de sahâbe, mütekaddimûn ve müteahhirûn dönemlerinde sağlam hadis nüshası oluşturma gayretleri incelenmiştir. Üçüncü Bölüm’de ise muhaddislerin sağlam nüsha oluşturma yöntemiyle tarihçi ve edebiyatçıların yöntemleri kısaca karşılaştırılmıştır.

İlk bakışta kitabın konusunun, bir hadis eserinin veya hadis hocasının "asl"ının orijinaline uygun yeni bir nüshasını üretme faaliyeti olduğu izlenimi uyansa da yazarın sağlam nüsha oluşturma amacına matuf metin tenkidi faaliyetine farklı anlamlar yüklemesi okuyucunun zihnini karıştırmaktır. Zira araştırmanın kaynakları içerisinde "yazılı bir eserin belirli bir yöntem çerçevesinde aslına uygun yeni bir nüshasını oluşturma" anlamındaki metin tenkidine yoğunlaşan kitapların yanı sıra "çeşitli dış kriterler ışığında muhtevasını tenkit ederek hadisin shhatini, Hz. Peygambere aidiyetini tespit etme" anlamindaki metin tenkidi kitapları da zikredilmektedir. ${ }^{2}$ Yazarın, onlara eser boyunca atıf yapmaması veya sadece bir iki atıfla yetinmesi bir yana "muhteva tenkidine" yönelik kitapları zikretmesi akla "Yazar metin tenkidi ile neyi kastetmektedir?" sorusunu getirmektedir. Bu karmaşa ve belirsizliğin "Kavramsal Çerçeve" başlığı altında bir nebze olsun giderileceği umulurken yazar bu hususa dair herhangi bir açıklama yapmaz. Ancak Birinci Bölüm'de Batılı tarihçilerle edebiyatçıların metin tenkidi faaliyetleri ve yöntemleri ele alınırken yeniden yazarın ilgili kavramla "bir eserin orijinal haline uygun yeni bir nüshasını oluşturma faaliyetini” kastettiği izlenimi edinilir.

\footnotetext{
* Arş. Gör. Marmara Üniversitesi Sosyal Bilimler Enstitüsü, Hadis Bilim Dalı, mustafa.avni@marmara.edu.tr Orcid No: 0000-0002-0143-9686

1 Hadiste Sağlam Nüsha Oluşturma Çalışmaları, Ankara: Mânâ Ajans Yayınları, 2019.

2 Gurbet, Sağlam Nüsha, s. 21-36.
} 
"Metin tenkidi, esas nüsha metnini veya o metne en yakın (constitio textus) bir metni meydana koymak maksadıyla yapılan iştir" ${ }^{3}$ ifadesi bu yargıyı desteklerken sadece bir paragraf sonra muhteva tenkidinin 4 "metin tenkidi” olarak nitelenmesi mevcut karışıklığı artırır. Bu karmaşa, kitabın ilerleyen sayfalarında sürerken yazar "Hadisçilere Göre Metin Tenkidi" başlığı altında metin tenkidine geniş bir anlam yüklediğini ifade etmektedir. Nitekim kitabın sonuna kadar metin tenkidi hakkındaki kavram kargaşası devam etmektedir.

Bir kelime veya terkip birden fazla anlamda kullanılabilir. 6 "Metin tenkidi" kavramı da Gurbet'in "Kitabın Kaynakları” başlığı altında zikrettiği akademik çalışmalarda görüldüğü üzere bu duruma örnektir. Nitekim bir grup akademisyene göre terkip, metnini birtakım kriterler ışı̆̆ında tenkide tâbi tutarak hadisin sıhhatini tespit faaliyetini, diğer bir gruba göre ise bir eserin aslına uygun yeni bir nüshasını oluşturma çabasını ifade eder. Gurbet ise metin tenkidi kavramını herhangi bir ayrıma gitmeksizin her iki anlamda da kullanmıştır. Aynı kelimelerle ifade edilse de bunlar farklı faaliyetlerdir. Dolayısıyla aralarında kategorik bir ilişki ve örgü kurularak veya birbirinden ayrı olarak incelenmelidir. Ancak Gurbet, bu tarz bir ayrım gözetmemiş ve bir faaliyetten bahsederken diğerine atıf yapabilmiştir.

Çalışmasını anlaşılır kılmak adına yazardan açıklığa kavuşturması beklenen en temel ifade "sağlam nüsha oluşturma" tamlamasıdır. Ne var ki kitaba başlık olarak seçilen bu terkip açıklanmamıştır. Bundan dolayı metin tenkidi kavramındaki karmaşa ve belirsizlik, "hadiste sağlam nüsha oluşturma” terkibi için de söz konusudur. Yazarın bu kavramla "bir kişinin çeşitli hacim ve özelliklere sahip orijinal bir eseri kaleme almasını"7 $\mathrm{ml}$, "daha önce biri tarafından telif edilmiş bir eserin aslına en uygun biçimde yeni bir nüshasının oluşturulmasını" 8 mı, yoksa "sağlam hadisleri içeren orijinal nüshalar telif etmeyi"9 mi kastettiği belirsizdir. Örneğin Batı ve İslâm âlemindeki metin tenkidi faaliyetlerinin, muhaddislerin sağlam nüsha oluşturma amaçlı nüsha mukabelesi faaliyetlerinin ve nüshalardaki hataları, fazlalıkları veya düşmeleri düzeltmeye dair belirledikleri kuralların ele alınması bu terkiple "bir müellife ait yazılı bir hadis eserinin aslına en uygun biçimde yeni bir nüshasının oluşturulmasının" kastedildiğini düşündürse de eserde bu yargıyı ortadan kaldıran ifadeler yer alır. Nitekim hadisçilerle edebiyatçıların sağlam nüsha oluşturma yöntemleri karşılaştırılırken Kaşgarlı Mahmud'un Dîvânu lügâti't-türk'ü ve Wilhelm Radloff'un Manas Destaninı Türk kabilelerini gezerek telif ettikleri belirtilip "Edebiyatçıların ezberde bulunan bilgilerden sağlam nüsha

Gurbet, Sağlam Nüsha, s. 51.

Gurbet, Sağlam Nüsha, s. 51-2.

Gurbet, Sağlam Nüsha, s. 85 .

Söz gelimi "haber" kelimesini kelam, usûl ve mantık âlimleri "yalan veya doğru olma ihtimali taşıyan söz", muhaddisler ise "Hz. Peygamber'e ait söz, fiil, onay, ahlaki veya fiziksel özellik gibi bilgileri içeren söz" anlamında kullanır. "Asl” kelimesi de "istıshab", "icmalî şerî delil”, "tafsîlî şerî delil”, "esas veya baskın anlam”, "küllî kaide”, "kıyas ameliyesinde esas alınan hükmü belli şey”, "şeyhin mesmuâtını içeren hadis kitabı", "hadis rivayet eden şeyh/hoca”, "isnat” gibi değişik anlamlarda kullanılmıştır.

7 Gurbet, Sağlam Nüsha, s. 211, 293.

8 Gurbet, Sağlam Nüsha, s. 191.

9 Gurbet, Sağlam Nüsha, s. 19, 150-1, 211. 
oluşturmaya çalışmaları ve sağlam nüsha oluşturmak için yapmış oldukları tüm bu seyahatler hadisteki ezberlemeye ve rihleye benzese de bu faaliyetler hadiste olduğu gibi sistematik bir faaliyet değil bilakis bireysel faaliyetlerdir" ${ }^{\prime 10}$ denir. Böylece şifâhî bilgileri kaydederek orijinal bir eser derlemek de sağlam nüsha oluşturma kapsamına alınır. Hâlbuki yazar birbirinden farklı olan üç faaliyeti de sağlam nüsha oluşturma faaliyeti olarak görüyorsa bunu eserinde net bir üslupla belirtmeliydi.

Yazarın en büyük problemlerinden biri şüphesiz kronolojik bir bakış açısına sahip olmayışı veya olsa da bunu çalışmasına yansıtmamasıdır. O, sağlam nüsha oluşturma çabalarını "sahâbe", "mütekaddimûn" ve "müteahhirûn" dönemi diye üçe ayırarak işler. Bu dönemlendirmede hangi tarih ve kriterleri dikkate aldığını da açıklar. ${ }^{11}$ Ancak söz konusu dönemlendirme kitap içerisinde neredeyse hiç dikkate alınmamış, sadece başlıkta kalmıştır. Zira yazar, mütekaddimûn dönemi sağlam nüsha oluşturma faaliyetleriyle ilişkilendirdiği konularda sıkça sahâbe döneminden, hatta hadislerden örnekler vermiştir. ${ }^{12}$ Kronolojik gelişim çizgisini göz ardı etme tavrı, müteahhirûn dönemi sağlam nüsha oluşturma çabaları bağlamında da sürdürülmüş, bu dönem tasvir edilirken mütekaddimûn dönemi -dahası sahâbe dönemi- uygulamaları anılabilmiştir. ${ }^{13}$

Yazar, hadis öğrenim, öğretim ve yazımına dönük usûl ve kavramların nispeten değişikliklere uğrayarak istikrar bulduğu dönemlerde yazılmış hadis usûlü eserlerindeki yargıları mütekaddimûn dönemine teşmil etmiştir. Nitekim o, mütekaddimûn döneminde sağlam nüsha oluşturma çalışmaları sadedinde isimlerin yanlış okunmasını önlemek için harekeleme ve noktalamaya önem verildiğini vurgulayıp Hatîb el-Bağdâdî ile Râmhürmüzînin açıklamalarını alıntılar ${ }^{14}$ ve onların sözlerini tâbiûnu da kapsayan mütekaddimûn dönemine teşmil eder. İbrahim en-Nehaî, Hasan el-Basrî, İbn Sîrîn ve Katâde gibi tâbiî âlimlerin Kurân’ın noktalanmasına dahi karşı çıkmaları, bazı âlimlerin ilk iki asırda noktalama ve harekelemenin hadis sahasında yaygın olmadığını belirtmeleri ve bundan dolayı tashif ve tahrife sebep olabilecek vicâde, münâvele, i'lâm, vasiyet ve icâzet gibi yöntemlerle rivayete sıcak bakılmaması ve erken dönemde önemli muhaddislerin bile tashif ve tahrif yaptıklarına dair örnekler bu husustaki genellemenin isabetli olmadığını gösterir. ${ }^{15}$ Yazar, Kadı İyâz ve Râmhürmüzîye referansla işlediği hadis usûlü konularının genelinde dönemsel ayrım ve yaklaşım farklılıklarını dikkate almayıp genelleyici yargılara varmıştır.

Dönemsel uygulama ve anlayış farklılıkları, zamansal değişim ve kronolojik gelişimi göz önünde bulundurma izlenimi uyandırmasına rağmen yazar, mütekaddimûn döneminde ele

10 Gurbet, Sağlam Nüsha, s. 293.

11 Gurbet, Sağlam Nüsha, s. 137.

12 Gurbet, Sağlam Nüsha, s. 146, 161, 168, 170, 176.

13 Gurbet, Sağlam Nüsha, s. 240, 241-2, 244, 247-8, 267, 277-8.

14 Gurbet, Sağlam Nüsha, s. 177-8.

15 Irakî, Fethu'l-muğı̂s, II, 101-8; Sehâvî, Fethu'l-muğı̂s, III, 19-20; Muhammed es-Sânî b. Ömer, Davâbit, s. 481-2; Humeyd, Târîhu'l-hatti'l-arabî, I, 295. 
aldığı birçok konuyu müteahhirûn döneminde yeni bir bakış açısı sunmadan tekrarlamıştır. Her iki döneme dair müstakil başlıklar açarak tekrara düştügü konuların bazıları şunlardır: "Hadis Talebesinin Hadis Alabilmesi İçin Gerekli Olan Yaş Sınırı, Hadis Talebesinin Vasıfları, Ahlâkı, Âdabı, Hadisleri Lafzını Değiştirmeden Rivâyet Etmeye Teşvik, Muhaddislerin Hadis Yazmaya Teşvik Edilmesi, Yazılışları Aynı Olan İsimlerin Harekelenmesi, Nüshaların Kontrol Edilmesine ve Tashihine Önem Verilmesi, Hadis Nüshasında Tespit Edilen Hataların (Tashifât) Düzeltilmesi, Nüsha Mukabelesi Yapılması, Hak (Kazımak) ve Darb (Kelimenin Üzerine Çizgi Çekmek)'da Dikkat Edilecek Hususların Belirlenmesi, Sağlam Nüsha Oluşturmak Maksadıyla Rıhle Yapılması, Sağlam Nüsha Oluşturmak Gayesiyle Râvilerin İsim, Künye ve Lakaplarının Araştırılması, İcâzet, Münâvele, Kitâbet, Vasiyyet ve Vicâde ve Diğer Yöntemlerin Kullanılması, Hadislerin Ezberlenmesi." Yazarın her iki dönemdeki farklılıklara, dönemsel gelişim ve değişime yoğunlaşarak bütün bu konuları ayrı ayrı ele alması belki anlamlı olabilirdi. Ancak eserde böyle bir bakış açısı ve kronolojik okuma tavrı benimsenmemiş, daha önce belirtildiği üzere mütekaddimûn dönemine dair yargılarda sahâbe; müteahhirûn dönemine dair yargılarda da sahâbe ve mütekaddimûn uygulamalarına yer verilmiştir.

Eserde, sağlam nüsha oluşturma faaliyetiyle ilgisiz bazı konular incelenmiştir. Nitekim "Hadislerin Ehil Olmayan Kişilere Nakledilmemesi, Hadisleri Lafzını Değiştirmeden Rivayet Etmeye Teşvik, Hadis Talebesinin Vasıfları, Ahlâkı ve Âdabı, Bir Hadis Hakkında Yeterli Bilgiye Sahip Olmadan Söz Söylememeye Dikkat Edilmesi, Garib ve Şâz Rivayetlerin Reddedilmesi, Hadisçilerde Bulunması Gereken Niteliklerin Bilinmesi, Muhaddislerin Eserlerinde "Esmâ ve'l-Künâ" ve "Elkâb” Konularına Yer Vermeleri, Hadisleri Yazma, Tespit ve Semâda Müteşeddit ve Mütesâhil Davrananların Tespit Edilmesi” konuları sağlam nüsha oluşturma ve metin tenkidiyle ilgili değildir. Öte yandan konuyla ilgisi kurulabilecek konular ise bu yönde bir çaba sarf etmeksizin belirli birkaç hadis usûlü eseri üzerinden ve kimi zaman yoğun tercümelerle işlenmiştir. Söz gelimi yazar "İcâzet, Münâvele, Kitâbet, Vasiyyet ve Vicâde ve Diğer Yöntemlerin Kullanılması" başlı̆̆ı altında hadis öğrenim metotlarının mahiyeti ve meşruiyetine ilişkin yüzeysel açıklamalarda bulunmakla yetinmiş, ${ }^{16}$ mütekaddimûn dönemi sağlam nüsha oluşturma çabalarıyla ne türden bir ilişkisi olduğuna değinmemiştir.

Kitap değerlendirmesinde cevabı aranan en önemli soru şüphesiz "Okunan kitap orijinal midir, alana yeni bir katkı sağlamış mıdır?” sorusudur. Yazarın "sağlam nüsha oluşturma" ve "metin tenkidi” konusundaki zihin karışıklığı aslında bu sorunun cevabına dair ipuçları verir. Yine de her bölümü kısaca ve ayrı ayrı değerlendirerek bu hususa açılık getirilmelidir. Öncelikle dünden bugüne Batı ve İslâm dünyasındaki metin tenkidi çalışmaları incelenen kitabın Birinci Bölüm'ünde, söz gelimi Salahattin Polat'in Metin Tenkidi adlı çalışmasının üzerine bir şey konulmamıştır. Ancak bölümün, kitabın temel konusu olmadığı ve muhaddislerin yöntemiyle mukayese etmek için kaleme alındığ düşünüldüğünde orijinallik 
ve alana katkı beklentisi uygun olmayacaktır. Sahâbe, mütekaddimûn ve müteahhirûn dönemlerinde sağlam nüsha oluşturma faaliyetlerine tahsis edilen ve kitabın temel konusu olan İkinci Bölüm ise klasik hadis usûlüne aşina herkesin bildiği, başlıklardan içeriği tahmin edebildiği konulardan ibarettir. Belki bu konuların sağlam nüsha oluşturma açısından değerlendirilmesi orijinal olarak görülebilir. Ancak yazar daha önce de belirtildiği üzere ilgisiz birçok konuyu sağlam nüsha oluşturma ile ilişkilendirmiş, konularla tezi arasında güçlü ilişkiler kuramamıştır. Muhaddisler ile tarihçi ve edebiyatçıların sağlam nüsha oluşturma yöntemlerinin mukayesesine ayrılan 20 sayfalık Üçüncü Bölüm ise Birinci ve İkinci Bölümün özeti gibidir. Sonuç kısmı ise kitabın genel bir özeti mahiyetindedir.

Kitabın takibini zorlaştıran hususlardan biri de belirli bir konu işlenirken ilgisiz konulara girilmesidir. Sözgelimi yazar muhaddislerin sağlam nüsha oluşturma amacıyla rihle yaptıklarını belirtip ilgisiz iki örnek verdikten sonra rihlenin konuyla ilgisi olmayan yönlerini inceler. ${ }^{17}$ Daha da dikkat çekici olan aynı konuyu müteahhirûn döneminde işlerken de mevzudan ayrılıp rihlenin faydalarını anlatmasıdır. ${ }^{18}$ Keza muhaddislerin sağlam nüsha oluşturma amacıyla yardımlaşmalarını ele alırken birden hadis öğrenmek isteyen talebelerin men edilmemesi ve geri çevrilmemesi konularına girer. ${ }^{19}$ Yazar kimi zaman da ele aldığ konuyla ilgisi olmayan örnekler verir. Yine muhaddislerin sağlam hadis nüshaları oluşturmak amacıyla yardımlaştıkları belirtildikten sonra bu iddiayı somut örneklerle delillendirmek için üç farklı olay zikredilir. Ne var ki her üç olayın da sağlam nüsha oluşturma amaçlı yardımlaşmayla ilgisi yoktur. Aksine rivayetlerin ikisi fikhî meselelere çözüm amaçlı âlimlerin birbirleriyle istişaresi, diğeri ise avâmın âlimlerden fetva sormasına dairdir. ${ }^{20}$ Yazar noktasız ve harekesiz olarak yazılışları aynı, okunuşları farklı isimlerin harekelenmesinden bahsederken konuyu somutlaştırma adına Râmhürmüzîden nisbe bilgisine dair bir örnek nakleder. ${ }^{21}$ Zikredilen örnekte "el-Bedrî̀" nisbesinin ilk bakışta çağrıştırdığı üzere Bedir Savaşına katılan anlamında değil Bedir kuyusunun bulunduğu mevkie uğrayan veya yerleşen anlamında olduğu açıklanır. Yine yazar bir grup muhaddisin hadis nüshalarındaki hataların düzeltilmesini savunduğunu delillendirmek amacıyla üç örnek zikreder. Ancak üçüncü örnek, nüshalardaki hataların düzeltilmesiyle değil, zayıf veya sika ayırt etmeksizin her râvinin rivayetlerinin muhaddislerce yazılması ancak sonrasında bunların müzakere edilerek birbirinden ayırt edilmesiyle ilgilidir. ${ }^{22}$

Kitapta dikkat çeken diğer bir husus da metin okunurken kolayca fark edilen tercüme

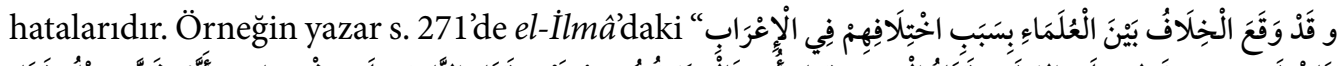

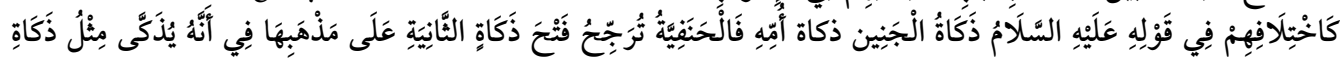

17 Gurbet, Sağlam Nüsha, s. 197-200.

18 Gurbet, Sağlam Nüsha, s. 239.

19 Gurbet, Sağlam Nüsha, s. 201-2.

20 Gurbet, Sağlam Nüsha, s. 200-1.

21 Gurbet, Sağlam Nüsha, s. 178.

22 Gurbet, Sağlam Nüsha, s. 181. 


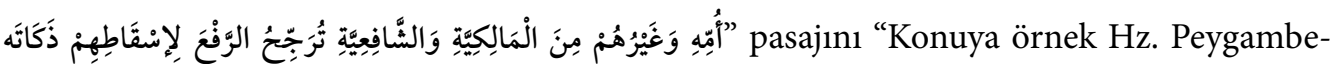
rin (as) (zekâtü'l-Cenini zekâte ümmihi) hadisinde ortaya çıkan farklı harekelemedir. Hanefiler burada ikinci (zekate) kelimesini (fetha) olarak kabul etmişler ve ceninin annesinin kesilmesiyle kesilmiş kabul edileceği görüşünü savunmuşlardır. Mâlikî ve Şâfiî, (refi) tercih etmişlerdir. Zekateyi düşürmüşlerdir"23 diye tercüme ederek Hanefîlere metinde atfedilen görüşün aksini nispet etmiş, ayrıca “" ibaresini "zekateyi düşürmüşlerdir” diye yarı transkripsiyon yarı da tercüme olarak okuyucuya takdim etmiştir. Söz konusu pasajın doğru tercümesi şöyle olmalıdır: "Âlimler, irab kaynaklı farklılıklardan dolayı [fıkhî hüküm belirlemede de] farklı görüşler ortaya koymuşlardır. Onların 'Annesinin kesilmesi ceninin kesilmesi anlamına gelir/Annesinin kesimi gibi cenin [de] kesilir' hadisinin [okunuşuna] dair ihtilafları bunun örneğidir. Nitekim Hanefîler annesi gibi [ceninin de] kesilmesinin gerektiği yönündeki görüşlerinden dolayı ikinci 'zekât/kesim' kelimesini fethayla okumayı tercih ederler. Şâfiîler ve Mâlikîler ise [ceninin] kesiminin gerekmediğini düşündükleri için merfû‘ okunuşunu benimserler." ${ }^{24}$

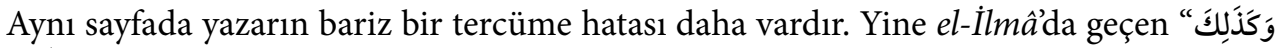

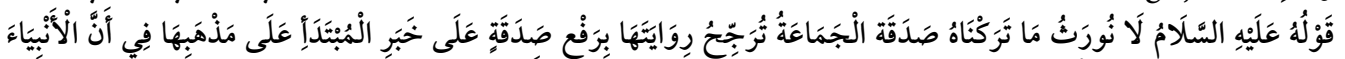

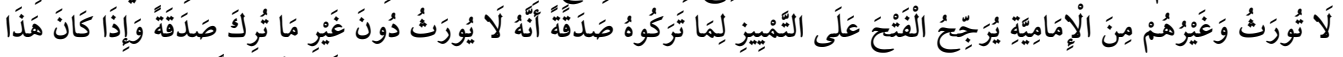

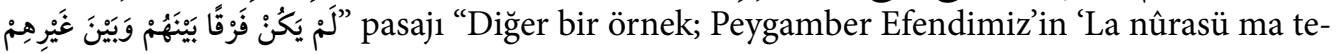
raknâhu sadegatün) hadisidir. Burada cemaat (sadegatün) kelimesini merfu yapmışlardır ve mübtedanın haberi olarak kabul etmişlerdir. Bu görüşte olanlar peygamberlerin miras bırakmadıklarını, onların bıraktıklarının sadaka olduğu görüşündedirler. İmâmiyye ise; fethayı tercih etmiş, peygamberlerin bıraktıklarını ayırmış ve 'Sadakadan başka bir şey bırakmamışlardır' şeklinde anlam vermiştir. Aslında ikisi arasında temelde fazla bir anlam farkı da yoktur" diye çevrilir. Gözleneceği üzere tercümede bariz hatalar yapılmıştır. Zira Fedek arazisine ilişkin sahâbe döneminde başlayan Sünnî-Şiî tartışmasını bilmek tercümedeki hatayı anlamak için yeterlidir. Nitekim yazar “[cümledeki konumu açısından "sadaka” kelimesini] temyiz olarak değerlendirmek suretiyle...” anlamındaki “ “عَلَى التَّمْيِيزِ “ibaresini lügat anlamı vererek "ayırmış(lar)" diye tercüme etmiştir. Doğru tercümesi "İmâmiyye ise [peygamberlerin] sadaka olarak bırakmadıkları şeylerin değil, sadaka olarak bıraktıkları şeylerin miras olarak değerlendirilemeyeceği anlamında [sadaka kelimesini] temyiz olarak konumlandırmak suretiyle fethalı okunuşu tercih etmiştir” olması gereken ibareyi de yukarıda kaydedildiği üzere Şîa’nın benimsemediği, daha doğrusu Ehl-i sünnet'in görüşüyle örtüşen bir surette çevirmiştir. Son cümledeki peygamberlere dönen muttasıl zamirleri Şı̂̉ya döndürerek vakıanın aksine Ehl-i Sünnet ile Şîa arasında temelde görüş ayrılığı olmadığını iddia etmiştir. Oysa

23 Doğrudan alıntılarda yazarın ifade ve imlalarına müdahale edilmemiş, olduğu gibi yansıtılmıştır.

24 Süfyân es-Sevrî, Mâlik, Ebû Yusuf, Muhammed eş-Şeybânî, Hasan b. Ziyâd, Şâfiî ve Ahmed b. Hanbel hamile hayvanın kesilmesi durumunda karnındaki yavrunun kesilmesinin gerekmediği görüşünden dolayı ölü olarak çıan ceninin helal olduğunu söylerler. Ebû Hanîfe ve Züfer ise kesilmesi gerektiğini düşündükleri için ölü çıan ceninin haram olduğu kanaatindedirler (bk. Nevevî, el-Mecmû́, IX, 145-8; Mehdî li-dinillah, el-Bahru'z-zehhâr, IV, 301; Mağribî, el-Bedru't-temmâm, IX, 379-384). 
öncesi ve sonrasından da anlaşılacağı üzere son cümlenin doğru tercümesi "Şayet [hadisin anlamı] böyle [yani Şî̉nın anladığı biçimde] olsaydı onlarla [peygamberlerle] başkaları arasında bir fark olmazdı" biçiminde olmalıdır.

Bunun dışında ilk bakışta anlaşılamayan ancak birtakım sebeplerle orijinal metne müracaat edilince yanlış tercüme edildiği anlaşılan örnekler de bulunmaktadır. Örneğin s. 246'da İsmail b. Râfi'ye nispet edilen söz aslında merfû‘ bir hadistir, Ancak yazar "Merfû olarak nak-

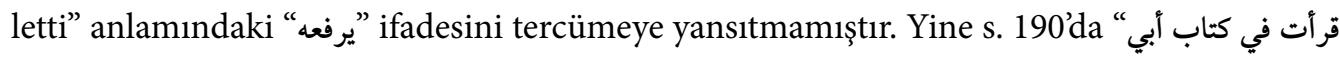
"ibaresi "Ebî Abdurrahim’in kitabindan okudum o da Muhammed İbn Seleme’den Ebî Abdurrahim hattiyla haber verdi o da Zeyd İbn Ebî Enîse'den..." diye çevrilmiştir. Hâlbuki ibarenin doğru çevirisi "Ebû Abdürrahîm'in kitabında okudum/gördüm -ki Muhammed b. Seleme bana onun Ebû Abdürrahîm’in kendi el yazısının ürünü olduğunu haber verdi- Zeyd b. Ebî Üneyse’den...” olmalidir.

Son olarak kitap imla ve yazım kuralları açısından incelenebilir. Kitabın en önemli kusurlarından biri şüphesiz hemen her sayfada karşılaşılan imla hataları ve standart problemleridir. Metin içerisinde geçen kitap isimleri bazen italik bazen düz kaydedilirken, ${ }^{25}$ özel isimlerin ilk harfi kimi zaman büyük kimi zaman küçük yazılır. ${ }^{26}$ Aynı sayfa veya satırda geçen bir kelime veya ifade dahi farklı farklı kaydedilir (İbn/b., Ebû/Ebî gibi). ${ }^{27}$ İsimlere kimi zaman irab uygulanır, kimi zaman uygulanmaz. ${ }^{28}$ Birçok isim ve nisbe yanlış yazılımıştır. ${ }^{29}$ Genelde bir hadisin veya Arapça ibarenin yalnızca tercümesi verilirken bazen çeviriyle birlikte orijinal metni de Arap alfabesiyle kaydedilir; ${ }^{30}$ kimi zaman da transkripte edilerek sunulur. ${ }^{31}$ Doğrudan alıntılar genelde çift tırnak kullanılmaksızın kaydedildiğinden adeta yazarın kendi yorumuyla harmanlanmış ifadeler olduğu sanılır. DİA'dan doğrudan alıntılanan s. 83’teki bir sayfalık uzunca pasaj buna örnek verilebilir. Noktalama işaretleri neredeyse her sayfada yanlış kullanıldığından bu duruma örnek vermeye gerek yoktur. Eserde paragraf olamayacak pasajlar müstakil paragraf yapılır. Kişilerin vefat tarihlerinin sık sık verilmesi bir yana bir kişinin vefat tarihinin aynı sayfada üç kere kaydedildiği bile gözlenir. ${ }^{32}$ Cümle sonlarında verilmesi gereken dipnot rakamları zaruret olmadığı halde cümle ortasındaki bir kelimeden sonra zikredilir, hatta ilginç bir şekilde kelimenin köküyle eki arasına dahi

25

Gurbet, Sağlam Nüsha, s. 83.

Örnek olmak üzere bk. s. 50-1 (Eski Ahit/eski ahit, Yeni Ahit/yeni ahit).

Örnek olmak üzere bk. s. 185 (İmam Ebî Bekr Muhammed İbn İshak b. Huzeyme, Ebû Bekr/Ebî Bekr).

Örnek olmak üzere bk. s. 90-1 (“Ukbe b. Abdillah”, “Abdu'l-Melik b. Muhammed b. Abdullah").

Örnek olmak üzere bk. s. 181'de "el-Kerâbîsî" yerine "el-Kürâbîsî", s. 183'te "Abdülhamîd" yerine "Abdu'l-Humeyd",

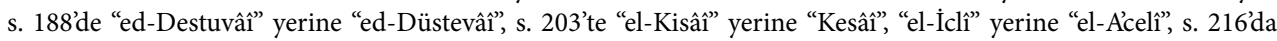
"Simâk b. Harb" yerine "Semmâk İbn Harb", "es-Süddî" yerine "Seddî", s. 252'de "Musa b. A'yen" yerine "Musa b. A'yun”, s. 260'da “İbnu’s-Sabbâğ" yerine "İbnu’s-Sabbâ", "el-Ğamrî” yerine "el-Kimerî”.

Gurbet, Sağlam Nüsha, s. 149, 194, 195, 235, 271.

Gurbet, Sağlam Nüsha, s. 271.

Örnek olmak üzere bk. s. 132 (Abdullah b. Amr), 139 (Râmhürmüzî, Evzâî). 
sıkıştırılabilir. ${ }^{33}$ Birkaç kişinin diyaloğunu içeren tercüme pasajlarda kimin ne söylediğini anlamak bazen hayli zordur. Daha da ilginç bir imla bozukluğu yazarın "...çünkü yazar alegori (sembol) ye, istihza (aldatma) ya, telmih (anımsatma) ya, mecazî sözlere (istiare, mübalağa, îcaz) başvurmuş olabilir” sözlerinde görülür. ${ }^{34}$

Usûl bilgileri açısından bariz hatalar içermemesine rağmen en temel konu ve kavramların mahiyetinin ve kapsamının netleştirilmemiş olması çalışma için ciddi bir problemdir. Öte yandan yazarın hadis usûlü meselelerini kronolojik bir bakış açısıyla inceleyemeyişi başlıklara yansıtılan dönemlendirmeyi anlamsızlaştırmıştır. İlgisiz konuların ele alınması, birçok konunun tekrar edilmesi, yoğun imla hataları ve standart problemleri kitabın değerini ciddi anlamda zedelemektedir. Dolayısıyla çalışmanın söz konusu tenkitler dikkate alınarak yeniden gözden geçirilmesi ve ikinci baskıda tavsiye niteliğindeki bu eleştirilerin dikkate alınması faydalı olacaktır.

Gurbet, Sağlam Nüsha, s. 60. 


\section{Kaynaklar}

Gurbet, Mahmut. Hadiste Sağlam Nüsha Oluşturma Çalışmaları. Ankara: Mânâ Ajans Yayınları, 2019. Humeyd, Abdülazîz. Târîhu'l-hatti'l-arabî abre'l-usûri'l-müteâkıbe. Beyrut: Dâru'l-Kütübi'l-İlmiyye, 2017. el-Irakî, Zeynüddîn Ebü'l-Fazl Abdürrahîm b. el-Hüseyin. Fethu’l-muğ̀is bi şerhi Elfiyyeti’l-hadîs (nşr. Mâhir Fahl). Beyrut: Dâru'l-Kütübi'l-İlmiyye, 2002.

el-Mağribî, Kadı Hüseyin b. Muhammed. el-Bedru't-temmâm şerhu Bulūği'l-merâm (nşr. Ali Abdullah ezZeben). Dâru Hecr, 1994.

Mehdî li-dînillah Ahmed b. Yahya b. Murtazâ. el-Bahru'z-zehhâr el-câmi‘ li-mezâhibi ulemâi'l-emsâr. Sana: Dâru'l-Hikmeti'l-Yemâniyye, 1988.

Muhammed es-Sânî b. Ömer. Davâbitu'l-cerh ve't-ta‘dîl inde’l-hâfiz ez-Zehebî̀, Leeds: Mecelletü'l-Hikme, 2000.

en-Nevevî, Muhyiddîn Yahya b. Şeref. el-Mecmû‘ şerhu’l-Mühezzeb (nşr. Muhammed el-Mutî‘̂i). Cidde: Mektebetü'l-İrşâd, ts.

es-Sehâvî, Şemsüddîn Ebü'l-Hayr Muhammed b. Abdurrahman. Fethu'l-muğ̣̂s bi-şerhi Elfiyyeti'l-hadîs (nşr. Abdülkerîm el-Hudayr). Riyad: Mektebetü’l-Minhâc, 2003. 